\title{
Arterial Stiffness and Anti-Tumor Necrosis Factor-Alpha Therapy in Ankylosing Spondylitis: Results With Long-Term Two Year-Follow-Up
}

\author{
Murat KARKUCAK, ${ }^{1}$ Erhan ÇAPKIN, ${ }^{1}$ Abdulkadir KİRİS,, ${ }^{2}$ Mürsel ŞAHİN, ${ }^{2}$ Ayşegül KÜÇÜKALİ TÜRKYILMAZ, \\ Adem KARACA, ${ }^{1}$ Ferhat GÖKMEN, ${ }^{1}$ Ahmet AYAR ${ }^{3}$ \\ ${ }^{1}$ Department of Physical Medicine and Rehabilitation, Medical Faculty of Karadeniz Technical University, Trabzon, Turkey \\ ${ }^{2}$ Department of Cardiology, Medical Faculty of Karadeniz Technical University, Trabzon, Turkey \\ ${ }^{3}$ Department of Physiology, Medical Faculty of Karadeniz Technical University, Trabzon, Turkey \\ ${ }^{4}$ Department of Physical Medicine and Rehabilitation, Medical Faculty of Recep Tayyip Erdoğan University, Rize, Turkey
}

\begin{abstract}
Objectives: This prospective clinical study aims to evaluate the effectiveness of long-term of anti-tumor necrosis factor-alpha (TNF- $\alpha$ ) therapy on arterial stiffness in ankylosing spondylitis.

Patients and methods: A total of 28 active ankylosing spondylitis patients ( 21 males, 7 females; mean age $33.5 \pm 9.5$ years; range 20 to 52 years) were enrolled. Patients' values for before the initiation of biological therapy and mid-term ( 24 weeks) evaluation were reported. For further evaluation, this initially reported patients were contacted two years after anti-TNF-a therapy, and their arterial stiffness was assessed by using pulse wave velocity. Results: After two years of anti-TNF-a therapy, despite the significant improvements in patients' symptoms and clinical activity parameters including Bath Ankylosing Spondylitis Disease Activity Index score $(4.9 \pm 0.9,1.9 \pm 0.5$ and $1.8 \pm 0.9, \mathrm{p}=0.0001)$, erythrocyte sedimentation rate $(35.5 \pm 23.1 \mathrm{~mm} / \mathrm{h}$, $13.8 \pm 9.2 \mathrm{~mm} / \mathrm{h}$ and $25.0 \pm 17.9 \mathrm{~mm} / \mathrm{h}, \mathrm{p}=0.0001)$, and C-reactive protein $(2.1 \pm 1.6 \mathrm{ng} / \mathrm{dL}, 0.4 \pm 0.3 \mathrm{ng} / \mathrm{dL}$ and $0.6 \pm 0.9 \mathrm{ng} / \mathrm{dL} \mathrm{p}=0.0001)$, no significant difference was observed in arterial stiffness parameters ( $7.9 \pm 1.3$ meter/second, $7.7 \pm 1.3$ meter/second and $8.3 \pm 1.1$ meter/second, $p=0.620)$.

Conclusion: In line with the previous 24-week evaluation, the results at two-year follow-up indicates that anti-TNF-a therapy does not improve arterial stiffness in patients with ankylosing spondylitis.

Key words: Ankylosing spondylitis; anti-tumor necrosis factor-alpha; arterial stiffness; pulse wave velocity.
\end{abstract}

Ankylosing spondylitis (AS) is a chronic inflammatory disease involving the sacroiliac joints and the spine, particularly. ${ }^{1}$ In the white population which has been studied more frequently, the prevalence of AS ranges between $0.5 \%$ and $1 \%$. The prevalence of AS is less than $0.5 \%$ in Turkey. ${ }^{2-4}$

Ankylosing spondylitis may show extraarticular manifestations, including cardiovascular $(\mathrm{CV})$ involvement. Among AS patients, the rate of $\mathrm{CV}$ involvement including aortic regurgitation, conduction defects, arrhythmias and pericardial abnormalities is estimated to be approximately $20-40 \% .^{5}$ Patients with AS may have an increased mortality compared to normal population, caused by increased CV risk in particular. ${ }^{6}$ The underlying causes for an increased incidence of $\mathrm{CV}$ disease are not precisely understood. However, inflammation may play an important role in the mechanisms leading to accelerated atherogenesis in patients with AS, and it is likely that chronic systemic inflammation contributes to the increased $\mathrm{CV}$ mortality and morbidity. ${ }^{7}$ Also, increased tumor necrosis factor-alpha (TNF- $\alpha$ ) levels may have an important role in the pathogenesis of vascular dysfunction in inflammatory diseases. Thus, 
it makes it necessary to focus on not only the clinical parameters of AS, but also on the $\mathrm{CV}$ disease markers including the arterial stiffness in the treatment of such patients. ${ }^{8}$

Recently, novel pathogenetic insights have attempted to identify the key role of TNF- $\alpha$ in inflammatory rheumatic diseases, and revolutionized the therapy of AS. AntiTNF- $\alpha$ treatments particularly inhibit the pro-inflammatory effects of TNF- $\alpha$. Clinical studies with anti-TNF- $\alpha$ treatment in AS have demonstrated superior efficacy to conventional treatments like non-steroidal anti-inflammatory drugs (NSAIDs) or disease modifying antirheumatic drugs. ${ }^{9}$

Arterial stiffness has been increasingly recognized as an important $\mathrm{CV}$ risk factor and an independent predictor of all-cause and CV death. ${ }^{9}$ Pulse wave velocity (PWV) and augmentation index (AIx) may be used particularly for the assessment of arterial stiffness. Pulse wave velocity which is reported to be a gold-standard measurement of arterial stiffness is a non-invasive method. ${ }^{10}$ Hence, PWV value has been used as an index for $\mathrm{CV}$ improvement following different treatment modalities in variety of conditions..$^{11,12}$ Our previous study revealed that PWV was higher in AS patients than in the control group. ${ }^{8}$ AntiTNF- $\alpha$ therapy has been associated with dramatic improvements in the clinical signs and symptoms of AS. ${ }^{13}$ Previously, we published the results for a 24-week follow-up of anti-TNF- $\alpha$ therapy in the same patient population, which indicated no beneficial effect on arterial stiffness. ${ }^{8}$

In addition to the fact that vascular structural changes may require longer time, the optimal follow-up period for observing the effects of anti-TNF- $\alpha$ therapy on arterial stiffness remains unknown, and longer-term consequences are still unclear. Hence, the objective of this prospective study is to reveal the effectiveness of a long-term follow-up for a two-year anti-TNF- $\alpha$ therapy on arterial stiffness, which was indicated by PWV, in patients with AS.

\section{PATIENTS AND METHODS}

This study was conducted between September 2009 and 2012. Twenty-eight patients (21 males,
7 females; mean age $33.5 \pm 9.5$ years; range 20 to 52 years) with AS were consecutively recruited. Assessments were performed at initial stage, $24^{\text {th }}$-week (intermediate follow-up time point) and two years after the initiation of therapy. All patients fulfilled the modified New York diagnostic criteria of AS, and were scheduled for antiTNF- $\alpha$ treatment according to the Assessment of SpondyloArthritis International Society (ASAS) guidelines. ${ }^{14,15}$ Informed consents were obtained before enrolment, and approval for the study was granted by the local ethical committee of the university. We excluded patients with diabetes mellitus (fasting blood glucose $>7 \mathrm{mmol} / \mathrm{L}$ ) and those on anti-hypertensive medications or lipidlowering therapies. Patients with a history of $\mathrm{CV}$ diseases (stroke, heart failure, myocardial infarction or angina, and peripheral vascular disease) were also excluded. Adherence to the current therapy was closely followed by ensuring that all of the patients received the planned medication during the reported follow-up period. The use of NSAIDs was not restricted. At the $24^{\text {th }}$ week of the evaluation, six patients ( 3 males and 3 females) declined to be involved for further analysis; therefore, these patients were not included in the two-year follow-up. The study was carried out in compliance with the principles of Helsinki Declaration. The study was approved by the Ethics Committees or Internal Review Boards of the participating institute.

The Bath Ankylosing Spondylitis Disease Activity Index (BASDAI) was used to show the disease activity (BASDAI: $0=$ no disease, $10=$ highest level of activity). ${ }^{16}$ The BASDAI, erythrocyte sedimentation rate (ESR) and C-reactive protein (CRP) levels were measured at the start, 24 weeks, and two years after therapy. Blood pressure was recorded with a mercury column sphygmomanometer. Patients were assessed by a single physician who were informed about the study protocol.

The body weight and height were assessed and body mass index (BMI) was calculated. Cervical, lumbar and special sacroiliac images were taken. Total cholesterol, triglyceride, high-density lipoprotein cholesterol, low-density lipoprotein cholesterol, ESR and CRP were measured after a night of fasting (8-12 hours). Total cholesterol and low-density lipoprotein cholesterol were measured at the initial stage and after the follow-up period. 
The carotid-femoral PWV was noninvasively assessed using the SphygmoCor system (AtCor Medical Pty Ltd, West Ryde, Sydney, Australia) with applanation tonometry. Patients were firstly rested for 15 minutes in the supine position before the measurement of PWV in a quiet and temperature-controlled room. Then, the distances from the carotid sampling site to the suprasternal notch and from the suprasternal notch to the femoral artery were measured. ${ }^{17}$ The carotid-femoral PWV was measured by sequential recordings of the arterial pressure waveform at the carotid and femoral arteries at the site of maximal arterial pulsation. The electrocardiogram was recorded simultaneously with the measurement of PWV. Then, the carotid-femoral PWV (in meters per second) was calculated automatically as the distance $(\Delta \mathrm{d})$ between the carotid and the femoral sampling site divided by the time interval $(\Delta t)$ between systolic R-wave and femoral systolic upstroke minus the time interval between systolic $\mathrm{R}$-wave and carotid systolic upstroke $(\mathrm{PWV}=\Delta \mathrm{d} / \Delta \mathrm{t})$. The carotid-femoral PWV was determined as the mean of at least three consecutive beats recorded during 10 seconds of data acquisition. Augmentation index is another arterial stiffness parameter and suggests the difference between early and late pressure peaks divided by central pulse pressure. ${ }^{17}$ To measure AIx, an ascending aortic pressure waveform was derived from the radial artery waveforms recorded at the wrist using applanation tonometry with a high-fidelity micromanometer. The aortic augmentation pressure (AP) was calculated as the difference between the first and second systolic peaks of the ascending aortic waveform, and AIx was expressed as a percentage of the central pulse pressure (the difference between the central systolic and diastolic pressures). In addition, AIx was standardized according to $75 \mathrm{bpm} / \mathrm{min}$ heart rate (HR) (AIx HR 75\%) to avoid the effect of heart rate. ${ }^{17}$ All measurements were performed by the same investigator without knowledge of the clinical and echocardiographic data. For reliable results, only high-quality recordings were included in the analysis. These were defined as acceptable curves on visual inspection and in-device quality index of $>80 \%$ derived from an algorithm including average pulse height, pulse height variation, diastolic variation, and the maximum rate of rise of the peripheral waveform. In this study, quality index was used instead of reproducibility, and the mean quality index was $91 \%$.

\section{Statistical analysis}

The normality of the distribution of data was evaluated by using the Kolmogorov Smirnov test for each group. The paired t-test was used for the comparison of variables with a normal distribution such as the high-density lipoprotein cholesterol, low-density lipoprotein cholesterol, triglyceride and total cholesterol values for the patient group. The repeated measures ANOVA (Bonferroni test as post hoc) was performed using the normal distribution for the AP, AIx AP, AIx HR, PWV, heart rate, BMI, systolic blood pressure, and diastolic blood pressure values for the patient group. The Friedman analysis (Wilcoxon test with Bonferroni correction as post hoc) was performed using the non-normal distribution for the BASDAI, CRP, and ESR values for the patient group. Continuous data were presented as mean and standard deviation. A $p$ value of $<0.05$ was considered statistically significant.

\section{RESULTS}

Table 1 summarizes the baseline clinical characteristics of the AS patients. After 24 weeks, six patients ( 3 males and 3 females) were withdrawn from the study at their own request. Most AS patients were human leukocyte antigen B27 (HLA-B27) positive (82\%), the median AS disease duration was $8.4 \pm 4.9$ years; and BASDAI disease activity score was 4.9 , which represents high disease activity. The anti-TNF- $\alpha$ treatment involved the use of the following three drugs: infliximab $=8$, etanercept $=13$, and adalimumab $=7$.

The baseline ESR, CRP and BASDAI score values were $35.5 \pm 23.1 \mathrm{~mm} / \mathrm{h}, 2.1 \pm 1.6 \mathrm{ng} / \mathrm{dL}$ and $4.9 \pm 0.9$, respectively. At the end of the study, ESR, CRP and BASDAI score values decreased significantly to $25.0 \pm 17.9 \mathrm{~mm} / \mathrm{h}, 0.6 \pm 0.9 \mathrm{ng} / \mathrm{dL}$ and $1.8 \pm 0.9$, respectively (Table 2).

There was no significant difference in PWV values between the pre-treatment, 24 weeks and post-treatment $(7.9 \pm 1.3$ meter/second, $7.7 \pm 1.3$ meter/second and $8.3 \pm 1.1$ meter/second, $\mathrm{p}=0.620$, Table 2) values. No significant change 
Table 1. Baseline clinical characteristics of the ankylosing spondylitis patients

\begin{tabular}{|c|c|c|c|}
\hline & $\mathrm{n}$ & $\%$ & Mean \pm SD \\
\hline Disease duration (years) & & & $8.4 \pm 4.9$ \\
\hline \multicolumn{4}{|l|}{ Sex } \\
\hline Male & 21 & & \\
\hline Female & 7 & & \\
\hline Age (years) & & & $33.5 \pm 9.5$ \\
\hline HLA-B27 positive & 23 & 82 & \\
\hline Current smokers & 12 & 42 & \\
\hline Body mass index $\left(\mathrm{kg} / \mathrm{m}^{2}\right)$ & & & $24.2 \pm 3.7$ \\
\hline Systolic blood pressure $(\mathrm{mmHg})$ & & & $107 \pm 14$ \\
\hline Diastolic blood pressure $(\mathrm{mmHg})$ & & & $66.8 \pm 11.5$ \\
\hline Total cholesterol (mg/dL) & & & $159.6 \pm 31.5$ \\
\hline LDL-C (mg/dL) & & & $87.3 \pm 22.1$ \\
\hline $\mathrm{HDL}-\mathrm{C}(\mathrm{mg} / \mathrm{dL})$ & & & $40.1 \pm 10.4$ \\
\hline Triglyceride (mg/dL) & & & $94.8 \pm 35.2$ \\
\hline BASDAI score & & & $4.9 \pm 0.9$ \\
\hline C-reactive protein (ng/dL) & & & $2.1 \pm 1.6$ \\
\hline $\mathrm{ESR}(\mathrm{mm} / \mathrm{h})$ & & & $35.5 \pm 23.1$ \\
\hline
\end{tabular}

was observed in the AIx HR 75\%, AP, and AIx $\mathrm{AP}$ values.

There were no significant differences between the values of lipid profiles, blood pressure and BMI at the initial stage, $24^{\text {th }}$ week, and after two years of follow-up.

\section{DISCUSSION}

Results from this study indicates that despite the marked improvement in clinical signs, the two- year follow-up of anti-TNF- $\alpha$ treatment did not significantly improve arterial stiffness in AS.

Epidemiological studies have shown that increased mortality in AS is largely attributable to $\mathrm{CV}$ disease. ${ }^{18}$ Since patients with AS have enhanced, but theoretically modifiable background risk of $\mathrm{CV}$ disease, therapy of $\mathrm{AS}$ requires more attention on preventing future $\mathrm{CV}$ disease.

The generalized inflammatory state that characterizes active AS may render these patients more prone to develop $\mathrm{CV}$ disease. Thus the association between chronic inflammatory diseases and $\mathrm{CV}$ disease attracts considerable attention. Still, the current evidence base for a link between AS and CV disease is limited. ${ }^{8,19}$ However, current data suggest that inflammation has a role in the development of endothelial impairment, and chronic inflammation leads to accelerated atherogenesis, particularly in rheumatoid arthritis and $\mathrm{AS}^{20}$

Pulse wave velocity is a marker for vascular dysfunction and an independent risk factor for CV disease. ${ }^{21}$ The measurement of aortic PWV is generally accepted as the most simple, noninvasive, and reproducible model to determine arterial stiffness. Measurement of the intima-media thickness (IMT) of the carotid artery is an important indicator for identifying early-stage atherosclerosis. ${ }^{22}$ Some studies focusing on the IMT of the carotid artery in AS patients and controls have been published. These studies found a non-significant trend toward a greater IMT in AS patients. ${ }^{23}$

Table 2. Comparison of clinical characteristics of the ankylosing spondylitis patients before and after treatment (at mid-term and long-term evaluation time points)

\begin{tabular}{|c|c|c|c|c|}
\hline & Before anti-TNF treatment $(n=28)$ & 24 week $(n=28)$ & 2 year $(n=22)$ & \\
\hline & Mean \pm SD & Mean \pm SD & Mean \pm SD & $p$ \\
\hline BASDAI & $4.9 \pm 0.9$ & $1.9 \pm 0.5$ & $1.8 \pm 0.9$ & 0.001 \\
\hline C-reactive protein (ng/dL) & $2.1 \pm 1.6$ & $0.4 \pm 0.3$ & $0.6 \pm 0.9$ & 0.001 \\
\hline Erythrocyte sedimentation rate $(\mathrm{mm} / \mathrm{h})$ & $35.5 \pm 23.1$ & $13.8 \pm 9.2$ & $25.0 \pm 17.9$ & 0.015 \\
\hline Body mass index $\left(\mathrm{kg} / \mathrm{m}^{2}\right)$ & $24.2 \pm 3.7$ & $24.5 \pm 3.9$ & $24.9 \pm 3.9$ & 0.540 \\
\hline Total cholesterol (mg/dL) & $162.2 \pm 39.9$ & - & $167.8 \pm 32.7$ & 0.415 \\
\hline Low-density lipoprotein cholesterol $(\mathrm{mg} / \mathrm{dL})$ & $90.9 \pm 24.4$ & - & $98.3 \pm 27.8$ & 0.067 \\
\hline Systolic blood pressure (mmHg) & $107 \pm 14$ & $108 \pm 11.8$ & $116.6 \pm 10.9$ & 0.546 \\
\hline Diastolic blood pressure (mmHg) & $66.8 \pm 11.5$ & $67.4 \pm 9.4$ & $74.4 \pm 7.8$ & 0.116 \\
\hline Heart rate & $74 \pm 11$ & $71 \pm 9$ & $71 \pm 12$ & 0.349 \\
\hline Augmentation pressure & $6.6 \pm 8.1$ & $5.1 \pm 5.5$ & $5.5 \pm 4.7$ & 0.642 \\
\hline Augmentation index augmentation pressure & $14.1 \pm 14.7$ & $15.5 \pm 17.7$ & $16.5 \pm 14.0$ & 0.978 \\
\hline Augmentation index heart rate $75 \%$ & $21.8 \pm 31.6$ & $11.8 \pm 18.4$ & $15.0 \pm 14.9$ & 0.063 \\
\hline Pulse wave velocity (meter/second) & $7.9 \pm 1.3$ & $7.7 \pm 1.3$ & $8.3 \pm 1.1$ & 0.620 \\
\hline
\end{tabular}


The optimal management of patients with AS requires a combination of non-pharmacological and pharmacological treatment modalities. The positive effects of anti-TNF- $\alpha$, which may be the most effective pharmacological treatment, on AS pain, functions, inflammation and extra-articular findings have been demonstrated. ${ }^{24}$ In our previous study, ${ }^{14}$ we have demonstrated the efficacy of a 24-week anti-TNF agents (infliximab $=8$, etanercept $=13$, and adalimumab $=7$ ) treatment in reducing the disease activity, with no changes in PWV. At two-year follow-up, treatment with anti-TNF- $\alpha$ demonstrated that significant clinical benefit at the intermediate follow-up time point (24 week) is durable, but still without any significant CV benefit as reflected by the PWV. Some modest changes occurred in the clinical characteristics of the patients (Table 2), but all of the parameters after these minor changes were still within normal ranges. Therefore, we conclude that despite the progress in current therapies in AS and significantly improved clinical signs, the consequences of $\mathrm{CV}$ structural changes still remain to be elucidated.

In a recent study, Mathieu et al. ${ }^{25}$ also assessed the effectiveness of TNF- $\alpha$ inhibitor treatment on arterial stiffness and $\mathrm{CV}$ risk, and despite the decrease in disease activity, reported no improvement in arterial stiffness after six and 12 months of therapy. Our early and current findings are in agreement with the latest study which involved a relatively larger patient population. ${ }^{8}$ Furthermore, our study not only supports the findings which suggest no significant changes in arterial stiffness in patients with AS after TNF- $\alpha$ blockade, but also provides new data on longer follow-up time point.

When evaluating the context of our research, one might ask how the values of arterial stiffness increased despite the relatively young group of patients (mean age $33.5 \pm 9.5$ ) with eight years of disease duration and good cholesterol values. Also, if it is possible to improve any impaired values with the therapy. Yet, there is no clear range of normative values for PWV, and a wellestablished level for the diagnosis of increased PWV. The latter constraint may be due to the introduction of this parameter to this field in the last decade. Therefore, studies particularly use pre-treatment values as reference (relying on stated disease impact) and investigate the effect of the therapy protocol on these baseline values, ${ }^{8,23}$ as in the current study. As it is already established and documented by researchers ${ }^{23}$ including our group, ${ }^{13} \mathrm{PWV}$ is higher in AS patients than in the control group. But this is not critical for the outcome of this study since the main aim was not to investigate whether the PWV values of AS patients are different from the healthy population, but rather to investigate the possible beneficial effect of antiTNF- $\alpha$ therapy on the arterial stiffness as indicated by PWV. Furthermore, this has been a subject for similar investigations accepting increased arterial stiffness as a fact of AS and investigating effects of therapy modalities on increased arterial stiffness. ${ }^{25}$ With regard to the age and disease duration of the study population, atherosclerosis can develop in young ages and even at childhood if risk factors or harming conditions exist. ${ }^{26,27}$ On the other hand, the evidently increased arterial stiffness despite these values of the study population presents another evidence for the significance of this surrogate morbidity risk factor for patients with AS. To the best of our knowledge, although similar studies using biological agents ${ }^{25}$ in AS therapy failed to demonstrate significant improvement in arterial stiffness, there are reports indicating that therapy, life style changes and invasive procedures may successfully reduce arterial stiffness. ${ }^{11,12}$ It has been shown that atorvastatin improves arterial stiffness through reduction of oxidative stress. ${ }^{28}$ We previously revealed that anti-TNF- $\alpha$ therapy reduces oxidative stress in patients with $\mathrm{AS}^{29}$ So, agents which reduce oxidative stress, if not those which reduce inflammation, may improve arterial stiffness.

A possible limitation of this study may involve the interpretation of the results since the patients were not evaluated between the $24^{\text {th }}$ week (the intermediate follow-up time point) and two-year time point. However, it is known that the natural course of atherosclerosis is progressive, and if no preventive intervention is performed, it may develop slowly, possibly avoiding any events from being missed during the time gap. There are several studies in the literature analyzing the natural progression of atherosclerosis, and the effects of therapy on disease regression. Those studies involve at least two time points ( $\min 24$ weeks) for 
evaluation. However, a three-year follow-up was performed in a PROSPECT study investigating the natural course of coronary atherosclerosis. ${ }^{30}$ In the current study, we evaluated the patients in two time points: at the $24^{\text {th }}$ week and after two years. Our patients did not present any significant change in lipid panels which might influence the atherosclerosis. Yet, the patients were not taking any drug which might affect the natural course of the atherosclerotic process. Additionally, this report assessed a small number of patients due to the withdrawal of six patients from follow-up; however, it is still possible to compare the baseline values of the involved patients. Also, one should be careful when interpreting the main findings of our study with regard to the clinical outcome due to the rather small sample size.

In conclusion, $\mathrm{CV}$ burden may play a significant role in AS-associated morbidity and mortality, and despite improved disease activity, the anti-TNF- $\alpha$ treatment does not seem to improve arterial stiffness in AS, even after a relatively long followup period of two years. However, further largescale researches are required to elucidate the effectiveness of anti-TNF- $\alpha$ treatment on arterial stiffness in AS.

\section{Declaration of conflicting interests}

The authors declared no conflicts of interest with respect to the authorship and/or publication of this article.

\section{Funding}

The authors received no financial support for the research and/or authorship of this article.

\section{REFERENCES}

1. Arnett FC. Ankylosing spondylitis. In: Koopman WJ, editor. Arthritis and Allied Condition. Philadelphia: Lippincott Williams and Wilkins; 2001. p. 1317-18.

2. Karkucak M, Cakırbay H, Capkın E, Topbaş M, Güler $\mathrm{M}$, Tosun $\mathrm{M}$, et al. The prevalance of ankylosing spondylitis in the eastern Black Sea region of Turkey. Eur J Gen Med 2011;8:40-5.

3. Onen F, Akar S, Birlik M, Sari I, Khan MA, Gurler O, et al. Prevalence of ankylosing spondylitis and related spondyloarthritides in an urban area of Izmir, Turkey. J Rheumatol 2008;35:305-9.

4. Cakır N, Pamuk ÖN, Derviș E, Imeryüz N, Uslu H, Benian Ö, et al. The prevalences of some rheumatic diseases in western Turkey: Havsa study. Rheumatol Int 2012;32:895-908.

5. Lautermann D, Braun J. Ankylosing spondylitis-cardiac manifestations. Clin Exp Rheumatol 2002;20:S11-5.

6. Papagoras C, Voulgari PV, Drosos AA. Atherosclerosis and cardiovascular disease in the spondyloarthritides, particularly ankylosing spondylitis and psoriatic arthritis. Clin Exp Rheumatol 2013;31:612-20.

7. Gonzalez-Juanatey C, Vazquez-Rodriguez TR, Miranda-Filloy JA, Dierssen T, Vaqueiro I, Blanco R, et al. The high prevalence of subclinical atherosclerosis in patients with ankylosing spondylitis without clinically evident cardiovascular disease. Medicine (Baltimore) 2009;88:358-65.

8. Capkin E, Karkucak M, Kiris A, Durmus I, Karaman K, Karaca A, et al. Anti-TNF- $\alpha$ therapy may not improve arterial stiffness in patients with AS: a 24-week follow-up. Rheumatology (Oxford) 2012;51:910-4.

9. Goh L, Samanta A. Update on biologic therapies in ankylosing spondylitis: a literature review. Int $\mathrm{J}$ Rheum Dis 2012;15:445-54.

10. Laurent S, Cockcroft J, Van Bortel L, Boutouyrie P, Giannattasio C, Hayoz D, et al. Expert consensus document on arterial stiffness: methodological issues and clinical applications. Eur Heart $\mathrm{J}$ 2006;27:2588-605.

11. Matthews PG, Wahlqvist ML, Marks SJ, Myers KA, Hodgson JM. Improvement in arterial stiffness during hypolipidaemic therapy is offset by weight gain. Int $\mathrm{J}$ Obes Relat Metab Disord 1993;17:579-83.

12. Matsuo $T$, Iwade $K$, Hirata $N$, Yamashita $M$, Ikegami $\mathrm{H}$, Tanaka $\mathrm{N}$, et al. Improvement of arterial stiffness by the antioxidant and antiinflammatory effects of short-term statin therapy in patients with hypercholesterolemia. Heart Vessels 2005;20:8-12.

13. Capkin E, Kiris A, Karkucak M, Durmus I, Gokmen F, Cansu A, et al. Investigation of effects of different treatment modalities on structural and functional vessel wall properties in patients with ankylosing spondylitis. Joint Bone Spine 2011;78:378-82.

14. van der Linden S, Valkenburg HA, Cats A. Evaluation of diagnostic criteria for ankylosing spondylitis. A proposal for modification of the New York criteria. Arthritis Rheum 1984;27:361-8.

15. Braun J, Pham T, Sieper J, Davis J, van der Linden $\mathrm{S}$, Dougados $\mathrm{M}$, et al. International ASAS consensus statement for the use of anti-tumour necrosis factor agents in patients with ankylosing spondylitis. Ann Rheum Dis 2003;62:817-24.

16. Garrett S, Jenkinson T, Kennedy LG, Whitelock H, Gaisford P, Calin A. A new approach to defining disease status in ankylosing spondylitis: the Bath Ankylosing Spondylitis Disease Activity Index. J Rheumatol 1994;21:2286-91.

17. Wilkinson IB, Fuchs SA, Jansen IM, Spratt JC, Murray GD, Cockcroft JR, et al. Reproducibility of pulse wave 
velocity and augmentation index measured by pulse wave analysis. J Hypertens 1998;16:2079-84.

18. Lehtinen K. Mortality and causes of death in 398 patients admitted to hospital with ankylosing spondylitis. Ann Rheum Dis 1993;52:174-6.

19. Peters MJ, van Eijk IC, Smulders YM, Serne E, Dijkmans BA, van der Horst-Bruinsma IE, et al. Signs of accelerated preclinical atherosclerosis in patients with ankylosing spondylitis. J Rheumatol 2010;37:161-6.

20. Sari I, Okan T, Akar S, Cece H, Altay C, Secil $\mathrm{M}$, et al. Impaired endothelial function in patients with ankylosing spondylitis. Rheumatology (Oxford) 2006;45:283-6.

21. Arnett DK, Evans GW, Riley WA. Arterial stiffness: a new cardiovascular risk factor? Am $J$ Epidemiol 1994;140:669-82.

22. Lekakis JP, Papamichael CM, Cimponeriu AT, Stamatelopoulos KS, Papaioannou TG, Kanakakis $\mathrm{J}$, et al. Atherosclerotic changes of extracoronary arteries are associated with the extent of coronary atherosclerosis. Am J Cardiol 2000;85:949-52.

23. Mathieu S, Joly H, Baron G, Tournadre A, Dubost JJ, Ristori JM, et al. Trend towards increased arterial stiffness or intima-media thickness in ankylosing spondylitis patients without clinically evident cardiovascular disease. Rheumatology (Oxford) 2008;47:1203-7.

24. Braun J, Sieper J. Treatment of rheumatoid arthritis and ankylosing spondylitis. Clin Exp Rheumatol 2009;27:S146-7.

25. Mathieu S, Pereira B, Couderc M, Rabois E, Dubost JJ, Soubrier M. No significant changes in arterial stiffness in patients with ankylosing spondylitis after tumour necrosis factor alpha blockade treatment for 6 and 12 months. Rheumatology (Oxford) 2013;52:204-9.

26. Robinson RF, Nahata MC, Sparks E, Daniels C, Batisky DL, Hayes JR, et al. Abnormal left ventricular mass and aortic distensibility in pediatric dialysis patients. Pediatr Nephrol 2005;20:64-8.

27. Celik T, lyisoy A, Kursaklioglu H, Turhan H, Cagdas Yuksel U, Kilic S, et al. Impaired aortic elastic properties in young patients with prehypertension. Blood Press Monit 2006;11:251-5.

28. Wang J, Xu J, Zhou C, Zhang Y, Xu D, Guo Y, et al. Improvement of arterial stiffness by reducing oxidative stress damage in elderly hypertensive patients after 6 months of atorvastatin therapy. J Clin Hypertens (Greenwich) 2012;14:245-9.

29. Karkucak M, Capkin E, Alver A, Akyuz A, Kiris A, $\mathrm{Ak} \mathrm{E}$, et al. The effect of anti-TNF agent on oxidation status in patients with ankylosing spondylitis. Clin Rheumatol 2010;29:303-7.

30. Stone GW, Maehara A, Lansky AJ, de Bruyne B, Cristea E, Mintz GS, et al. A prospective naturalhistory study of coronary atherosclerosis. $\mathrm{N}$ Engl $\mathrm{J}$ Med 2011;364:226-35. 